Provided for non-commercial research and education use. Not for reproduction, distribution or commercial use.

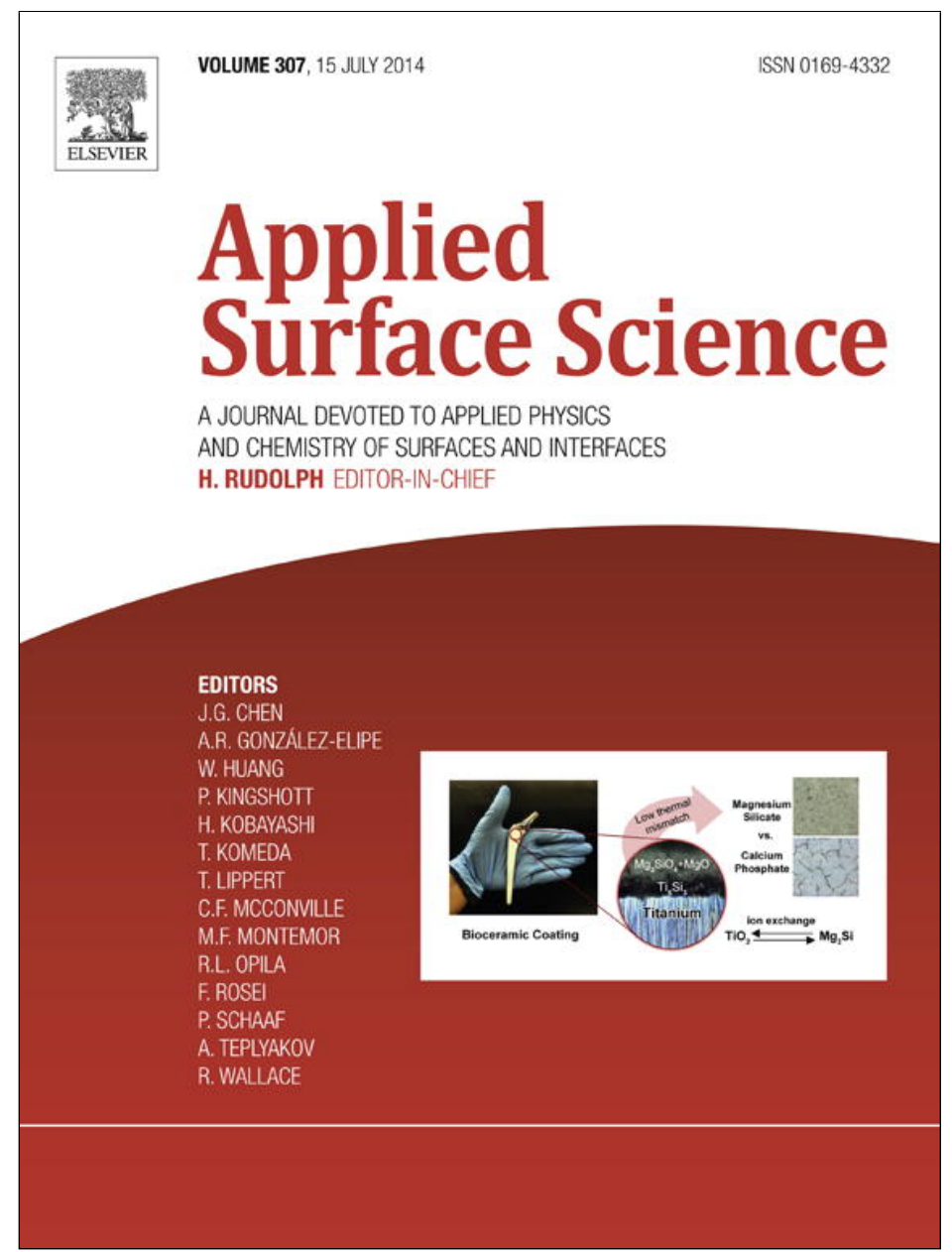

This article appeared in a journal published by Elsevier. The attached copy is furnished to the author for internal non-commercial research and education use, including for instruction at the authors institution and sharing with colleagues.

Other uses, including reproduction and distribution, or selling or licensing copies, or posting to personal, institutional or third party websites are prohibited.

In most cases authors are permitted to post their version of the article (e.g. in Word or Tex form) to their personal website or institutional repository. Authors requiring further information regarding Elsevier's archiving and manuscript policies are encouraged to visit:

http://www.elsevier.com/authorsrights 


\title{
Influence of thickness and coatings morphology in the antimicrobial performance of zinc oxide coatings
}

\author{
P. Carvalho ${ }^{a}$, P. Sampaio ${ }^{b}$, S. Azevedo ${ }^{a}$, C. Vaz ${ }^{b}$, J.P. Espinós ${ }^{c}$, V. Teixeira ${ }^{a}$, J.O. Carneiro ${ }^{a}{ }^{*}$ \\ a Department of Physics, University of Minho, Campus de Azurém, 4800-058 Guimaraes, Portugal \\ ${ }^{\mathrm{b}}$ CBMA, University of Minho, Campus de Gualtar, 4700 Braga, Portugal \\ ' Instituto de Ciencia de Materiales de Sevilla, CSIC-University of Sevilla, Avda. Américo Vespucio 49, 41092 Sevilla, Spain
}

\section{A R T I C L E I N F O}

\section{Article history:}

Received 31 January 2014

Received in revised form 13 March 2014

Accepted 8 April 2014

Available online 18 April 2014

\section{Keywords:}

ZnO thin films

Magnetron sputtering

Antimicrobial activity

Food packaging

\begin{abstract}
A B S T R A C T
In this research work, the production of undoped and silver (Ag) doped zinc oxide ( $\mathrm{ZnO}$ ) thin films for food-packaging applications were developed. The main goal was to determine the influence of coatings morphology and thickness on the antimicrobial performance of the produced samples. The $\mathrm{ZnO}$ based thin films were deposited on PET (Polyethylene terephthalate) substrates by means of DC reactive magnetron sputtering. The thin films were characterized by optical spectroscopy, X-Ray Diffraction (XRD), X-ray photoelectron spectroscopy (XPS) and Scanning Electron Microscopy (SEM). The antimicrobial performance of the undoped and $\mathrm{Ag}$-doped $\mathrm{ZnO}$ thin films was also evaluated. The results attained have shown that all the deposited zinc oxide and $\mathrm{Ag}$-doped $\mathrm{ZnO}$ coatings present columnar morphology with $\mathrm{V}$-shaped columns. The increase of ZnO coatings thickness until $200 \mathrm{~nm}$ increases the active surface area of the columns. The thinner samples $(50$ and $100 \mathrm{~nm}$ ) present a less pronounced antibacterial activity than the thickest ones (200-600 nm). Regarding Ag-doped ZnO thin films, it was verified that increasing the silver content decreases the growth rate of Escherichia coli and decreases the amount of bacteria cells present at the end of the experiment
\end{abstract}

(C) 2014 Elsevier B.V. All rights reserved

\section{Introduction}

More natural, safer and higher quality consumable products have been seen as a market demand of huge importance in what concerns the Food Packaging Industry. Foodborne illnesses and death is rising worldwide, particularly in developed countries [1]. Indeed, data from the Foodborne Diseases Active Surveillance Network (Food Net) states that comparing 2007 with 2004-2006, the estimated occurrence of infections caused by Campylobacter, Listeria, Salmonella, Shigella, Vibrio, and Yersinia did not diminished significantly, and above all, the incidence of Cryptosporidium infections even increased by $44 \%$ [2]. At the same time, foodborne illness-outbreaks create tremendous social and economic burdens bringing the fear for the re-emergence of infections diseases. Furthermore, the development of antibiotic resistance continues to draw public attention to food safety $[3,4]$. The combination of the supra-mentioned reasons with the current awareness for environmental conservation and protection has empowered the

\footnotetext{
* Corresponding author.

E-mail addresses: vasco@fisica.uminho.pt (V. Teixeira), carneiro@fisica.uminho.pt (J.O. Carneiro).
}

development of edible coatings and films from biodegradable materials to maintain the quality of both fresh and processed food [5].

Silver-based thin films [6,7] and zinc oxide nanoparticles [8-10] have emerged as promising candidates for active food packaging systems, particularly due to their antibacterial activity. However, due to the lack of knowledge regarding the interactions of nanosized materials at the molecular and physiological levels and their potential effects on human body, a major concern related to safety of nanoparticles for consumer's health is raising [11,12]. Titanium dioxide $\left(\mathrm{TiO}_{2}\right)$ has been used as a self-cleaning and self-sterilizing material to coat different tools, including sanitary ware, food tableware and cooking ware $[13,14]$. The antimicrobial effects of $\mathrm{TiO}_{2}$ are activated by its photocatalytic behaviour, which is totally dependent on ultraviolet and/or visible light irradiation. However, for food packaging industry this is a huge drawback since the antimicrobial activity will only be effective in irradiated packages. An alternative to overcome this limitation could be the use of Zinc oxide ( $\mathrm{ZnO})$. $\mathrm{ZnO}$ presents antimicrobial activity, can act as a permeation barrier coating [15] and is Generally Recognized as Safe material (GRAS) by the U.S. Food and Drug Administration (21CFR182.8991). In this sense, the development of zinc oxide thin films can be considered of great added value to food packaging 
industry. There are many scientific publications describing the interaction between $\mathrm{ZnO}$ nanoparticles and bacterial cells. However, as far the author's knowledge there are limited reported works concerning the evaluation of the antimicrobial activity of zinc oxide coatings deposited by means of reactive magnetron sputtering. In this sense, the main goal of this research work is to access the antimicrobial activity of zinc oxide coatings and study the influence of coating thickness, morphology and silver content in the antimicrobial activity. Its applicability for food packaging systems is also discussed.

To the author's knowledge, this work is the first to study the influence of thickness and coatings morphology on the antimicrobial activity, contributing to the knowledge of important physical variables in the thin films production.

\section{Materials and methods}

\subsection{Thin films production and characterization}

Zinc oxide thin films were deposited on Polyethylene Terephthalate (PET) substrates from Goodfelow and silicon (Si) substrates from Silllicon Materials by reactive DC magnetron sputtering (Advanced Energy Pinnacle Plus, 5K, DC Pulsed). The thin films deposited on PET were used for the evaluation of the optical properties and the antimicrobial activity and the ones deposited on $\mathrm{Si}$ were used for structural, morphological and compositional characterization. It was used a circular zinc target $(\Phi=75 \mathrm{~mm})$ with a purity of 99,9\% and a thickness of $4 \mathrm{~mm}$ acquired from Goodfellow Before deposition, the sputtering chamber [16] was pumped down to $10^{-3} \mathrm{~Pa}$. A gas atmosphere composed by argon (Ar, working gas) and oxygen $\left(\mathrm{O}_{2}\right.$, reactive gas) was used in the deposition processes. The $\mathrm{Ar}$ and $\mathrm{O}_{2}$ flows were kept constant at $70 \mathrm{sccm}$ (standard cubic centimetre per minute) and $18 \mathrm{sccm}$, respectively. Each deposition was carried out with a working pressure of $0.6 \mathrm{~Pa}$, a current of $0.35 \mathrm{~A}$ and a target/substrate distance of $80 \mathrm{~mm}$. Prior to each deposition the zinc target was pre-sputtered during $5 \mathrm{~min}$. All other deposition parameters were kept constant and the depositions were performed at room temperature $\left(40^{\circ} \mathrm{C}\right.$ measured inside the chamber). In order to study the influence of the coating thickness and morphology in its antimicrobial activity, the thickness was controlled by changing the deposition time. $\mathrm{Ag}$ pieces with purity of $99.99 \%$ were placed on the zinc target in order to promote the film doping effect.

X-ray diffraction (Philips PW 1710 X-ray diffractometer) analysis was used to investigate the crystallographic structure of $\mathrm{ZnO}$ thin films. The thickness and morphology of $\mathrm{ZnO}$ thin films were obtained by the observation of the cross section of the fractured thin films by SEM (NanoSEM-FEINOVA 200). The optical transmittance was measured by visible spectroscopy (Shimadzu UV-310PC scanning spectrophotometer). The chemical characterization was carried out by using a XPS spectrometer $(12 \mathrm{kV}, 20 \mathrm{~mA})$ from VG (ESCALAB 210), with the hemispherical electron energy analyser working in the constant pass energy mode at $50 \mathrm{eV}$ and unmonocromatized $\mathrm{Mg} \mathrm{K} \alpha(1253.6 \mathrm{eV})$ radiation as excitation source. Depth profiling was carried out by sequential ion bombardment with $\mathrm{Ar}$ ions of $3 \mathrm{keV}$ of kinetic energy. Since samples are bad electronic conductors, all spectra were calibrated against the position of the $\mathrm{Zn}_{2} \mathrm{p}_{3 / 2}$ at $1022.2 \mathrm{eV}$.

\subsection{Thin films antimicrobial activity}

In this research work, the Escherichia coli was the bacteria species chosen and it was obtained from the Centre of Molecular and Environmental Biology (CBMA), Department of Biology, University of Minho. A pre-culture was prepared for each individual batch experiment. One colony of E. coli strain HB101 was picked and loop inoculated into a $125-\mathrm{mL}$ Erlenmeyer flask, containing $20 \mathrm{~mL}$ of Luria Bertani (LB) broth $(10 \mathrm{~g} / \mathrm{L}$ tryptone, $10 \mathrm{~g} / \mathrm{L} \mathrm{NaCl}$, and $5 \mathrm{~g} / \mathrm{L}$ yeast extract). This pre-culture was incubated at $37^{\circ} \mathrm{C}$, for 12-15 h. On the day after, cells were transferred into different $250-$ mL Erlenmeyer flasks containing $50 \mathrm{~mL}$ of LB broth medium at a starting optical density (OD) of 0.1 measured at a wavelength of $640 \mathrm{~nm}$. A coated PET circular sample (diameter of $6 \mathrm{~cm}$ ), previously sterilized with $70 \%$ ethanol for $1 \mathrm{~h}$ and rinsed in sterile water, was deposited on the bottom of the flask. Flasks were then shaken at $80 \mathrm{rpm}$ in a temperature-controlled incubator at $37^{\circ} \mathrm{C}$, and the OD was monitored every hour. OD measurements were made using a Spectronic 20 instrument at $640 \mathrm{~nm}$ and the background (turbidity due to growth medium) was eliminated by taking blank readings. The specific growth rate $(\mu)$ was calculated from the exponential phase, according to the following equation:

$\mu=\frac{1}{t_{2}-t_{1}} \cdot \ln \left(\frac{O D_{2}}{O D_{1}}\right)$

where $O D_{1}$ and $O D_{2}$ are the optical densities corresponding to time instants $t_{1}$ and $t_{2}$, respectively. The generation time $\left(t_{g}\right)$ can be calculated according to the equation:

$t_{g}=\frac{\ln 2}{\mu}$

\section{Results and discussion}

\subsection{Thin films structure and morphology}

The produced $\mathrm{ZnO}$ thin films in this research work are highly transparent, presenting a transmittance of about $80 \%$ in the visible region of the electromagnetic spectrum. The remainder $20 \%$, is lost by reflection at the air/ZnO interface, by dispersion and by absorption of light in the substrate.

In order to study the influence of the coating thickness and morphology in its antimicrobial activity, the thickness was controlled by changing the deposition time. With this methodology it was observed that the film thicknesses ranged from 50 to $600 \mathrm{~nm}$. Xray diffraction analyses were performed in representative samples and the measurements were done between $20^{\circ}$ and $70^{\circ}(2 \theta)$ for all thin films. Fig. 1 shows the undoped zinc oxide X-Ray Diffraction patterns of the thin films having 50, 200 and $600 \mathrm{~nm}$ thicknesses.

In XRD patterns it is observed the presence of the $(002)$ diffraction peak of the ZnO wurtzite structure (JPCDS36-1451 [17]) in all the samples, indicating a preferential orientation to the c-axis

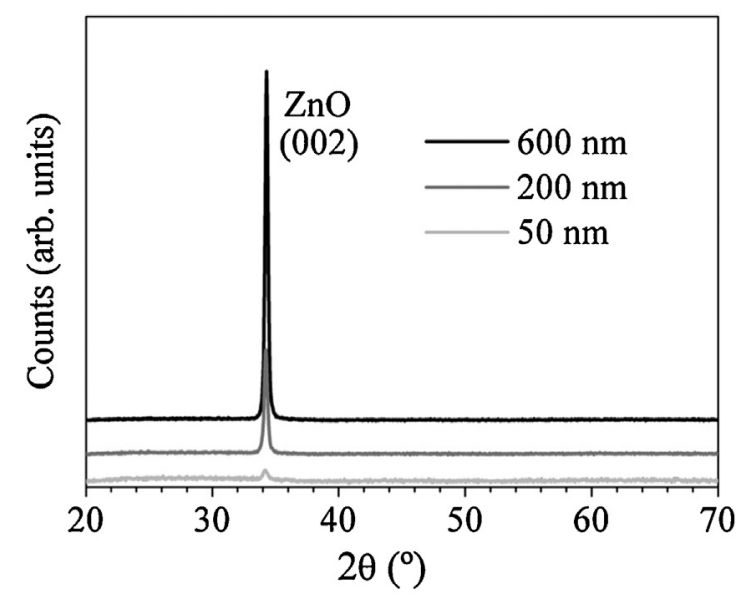

Fig. 1. XRD patterns of $\mathrm{ZnO}$ thin films with 50,200 and $600 \mathrm{~nm}$ thickness, deposited in PET substrate. 

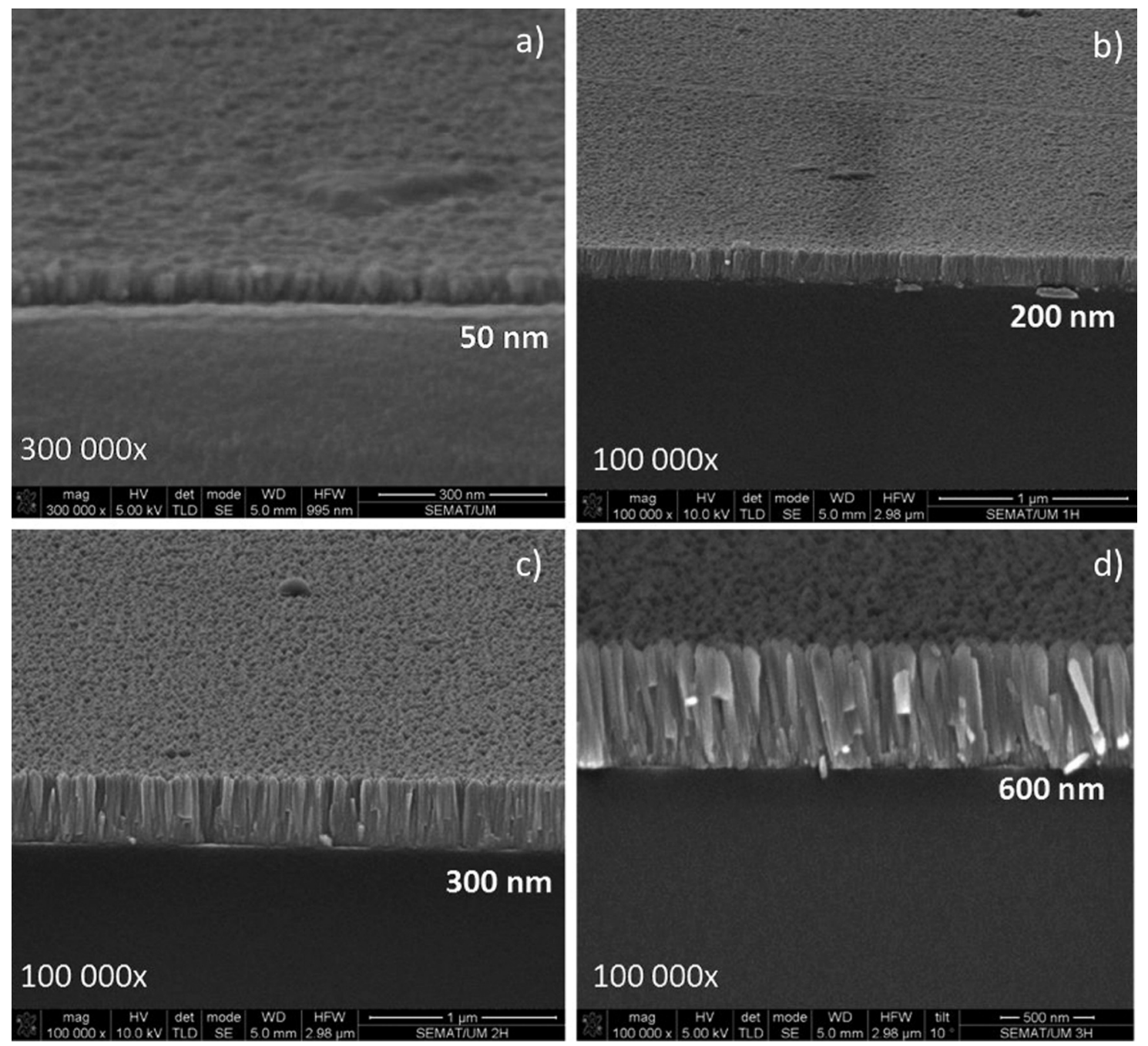

Fig. 2. SEM micrographs presenting the thin films cross-sections with different thickness deposited on Si substrate: (a) $50 \mathrm{~nm}$; (b) $200 \mathrm{~nm}$; (c) $300 \mathrm{~nm}$ and (d) $600 \mathrm{~nm}$.

perpendicular to the substrate, as previously reported by others authors $[18,19]$. Some authors correlate the preferential orientation with the minimization of internal stress and surface energy $[20,21]$ and others [22] reported that $c$-orientation maybe result from the highest atomic density found along $(002)$ plane. In Fig. 1 it is also possible to observe that, as expected, the increase of the coatings thickness induces an increase of diffraction peak intensity. The decrease of full width at half maximum also suggests an increase of grain size with the thickness.

Fig. 2 shows the SEM micrographs of the undoped $\mathrm{ZnO}$ samples cross-sections; the grains extend from the substrate to the top of the film. The typical morphology can be identified as a Zone 1 thin film of the modified structure zone model [23] with typically low compactness.

The thinner coatings, 50 and $100 \mathrm{~nm}$ (not showed here) present a more compact morphology in comparison with the thickest ones. It is possible to observe that the increase of coatings thickness induces the formation of less compact coatings, with well define and separated columns (Fig. 2). From this figure it is can also be identified an increase of columns width with the increase of coatings thickness. From the presented results it is also possible to conclude that a facet plane can be observed in the upper region for the thickest coatings (300-600 $\mathrm{nm}$ ). The attained results are in agreement with the ones reported by Shin et al. [24] that deposited ZnO coatings at room temperature on Si substrates. These authors explained the formation of facet planes as being a consequence of the lower diffusion rate of the atoms on the $\mathrm{ZnO}$ surface during column's growth the deposition rate.

To better understand the morphology of these coatings, top view SEM micrographs of $\mathrm{ZnO}$ samples with different thickness were taken and are shown in Fig. 3.

From Fig. 3 it is possible to perceive an increase of the top column width with the increase of the coating's thickness. Since the displayed images represent different $\mathrm{ZnO}$ coating's growth stages, it is plausible to assume that the deposited zinc oxide coatings have columnar morphology with V-shaped columns.

The formation mechanism of the V-shaped columnar structure has been thoroughly discussed and it is attributed to the competitive growth due to differences in surface energy of neighbouring crystal faces on the free surface of thin films [25,26]. A schematic illustration of the $\mathrm{ZnO}$ morphology with increasing thickness is presented in Fig. 4.

From the last schema it can be assumed that increasing the thin film's thickness beyond a certain value (that for these specific $\mathrm{ZnO}$ films is close to $300 \mathrm{~nm}$ ) may induce a decrease on the ratio of the columns surface area to columns length.

\subsection{Thin film antimicrobial activity}

The inhibition effect of the undoped zinc oxide coatings with different thicknesses on the growth rate of $E$. coli was evaluated by incubating bacteria cells with the different coatings in liquid media 

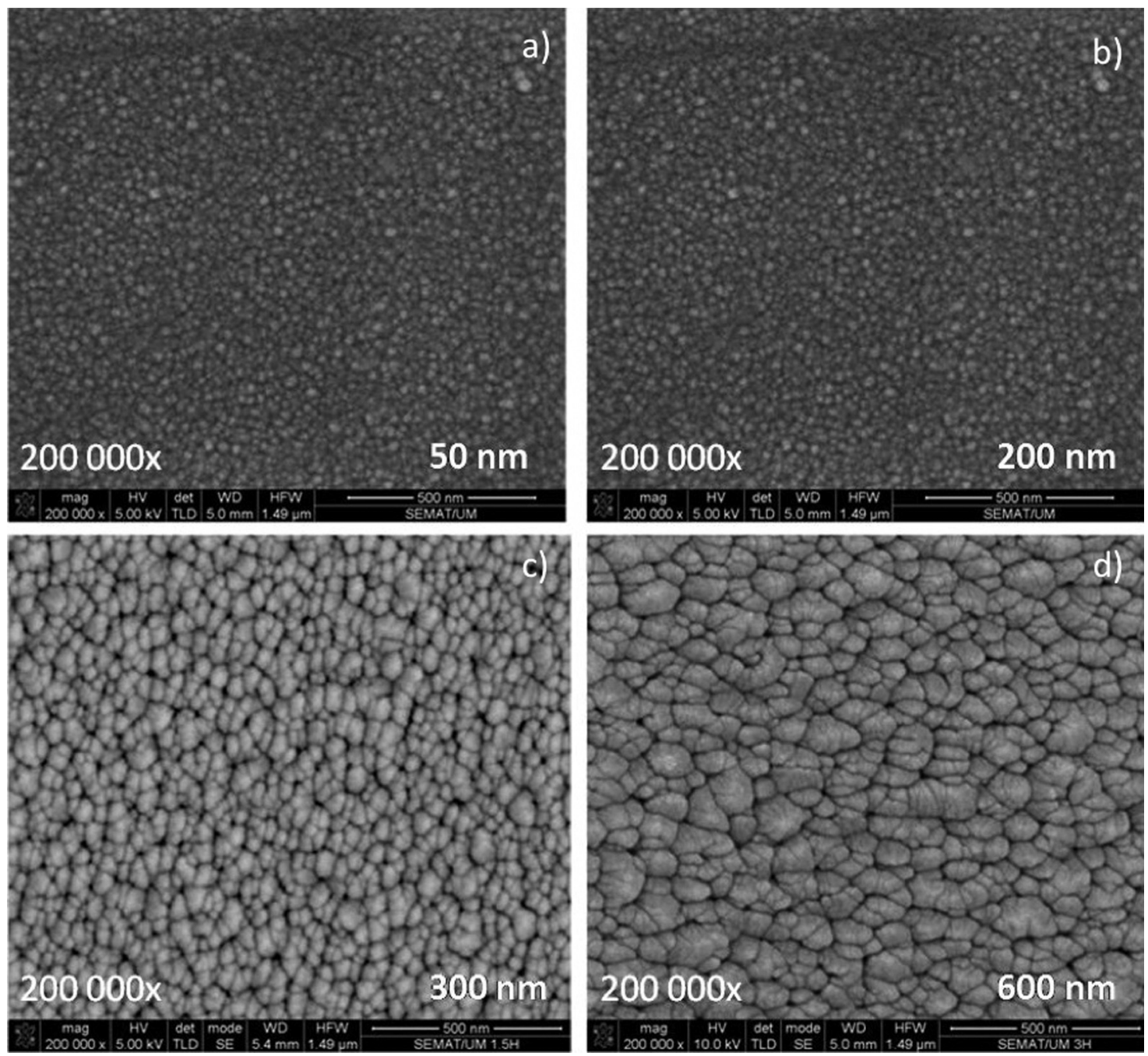

Fig. 3. Top-view SEM micrographs of ZnO thin films with different thickness deposited on Si substrate: (a) $50 \mathrm{~nm}$; (b) $200 \mathrm{~nm}$; (c) $300 \mathrm{~nm}$ and (d) $600 \mathrm{~nm}$.

at very low rotations to enhance the cell contact. Since the optical density (OD) is proportional to the number of microorganisms in the culture medium [27], lower OD indicates a higher antibacterial effect of the coated thin films. The bacterial growth was monitored over more than $24 \mathrm{~h}$ being possible to observe the cultures reaching the stationary phase, in which the microorganisms are no longer able to grow (Fig. 5a).

In fact, Fig. 5 shows that when comparing with the control, the thinner samples (50 and $100 \mathrm{~nm}$ ) present a less pronounced antibacterial activity than the thickest ones $(200-600 \mathrm{~nm})$. It is
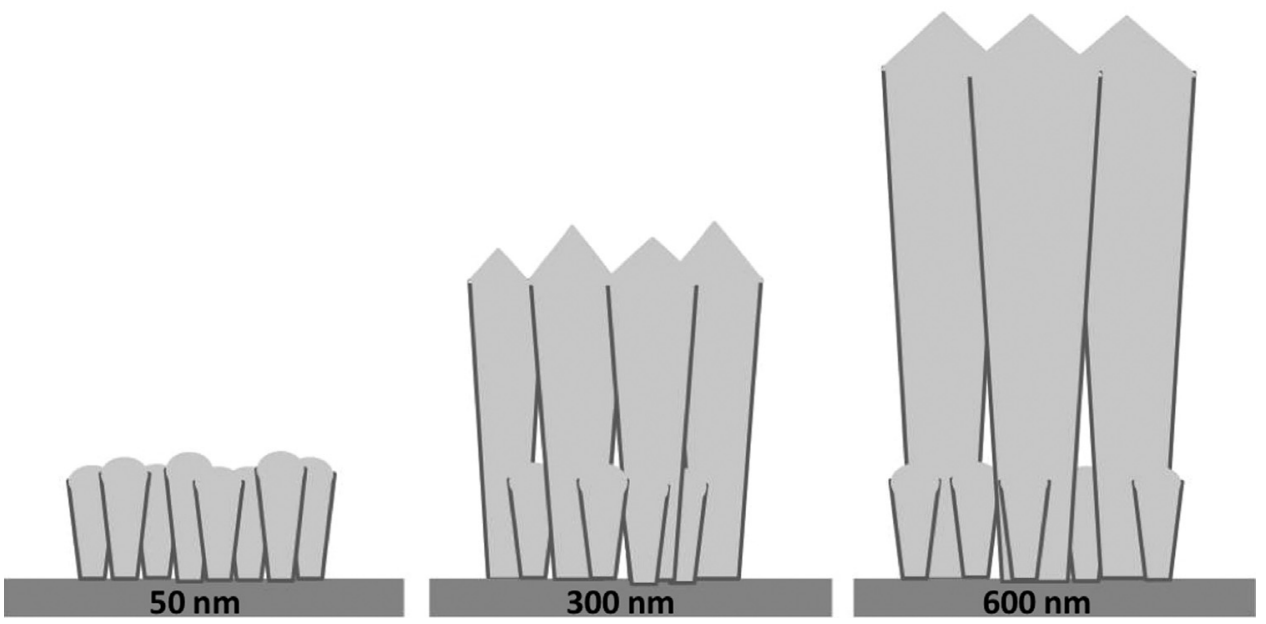

Fig. 4. Schematic draw of $\mathrm{ZnO}$ morphology with increasing thickness. 

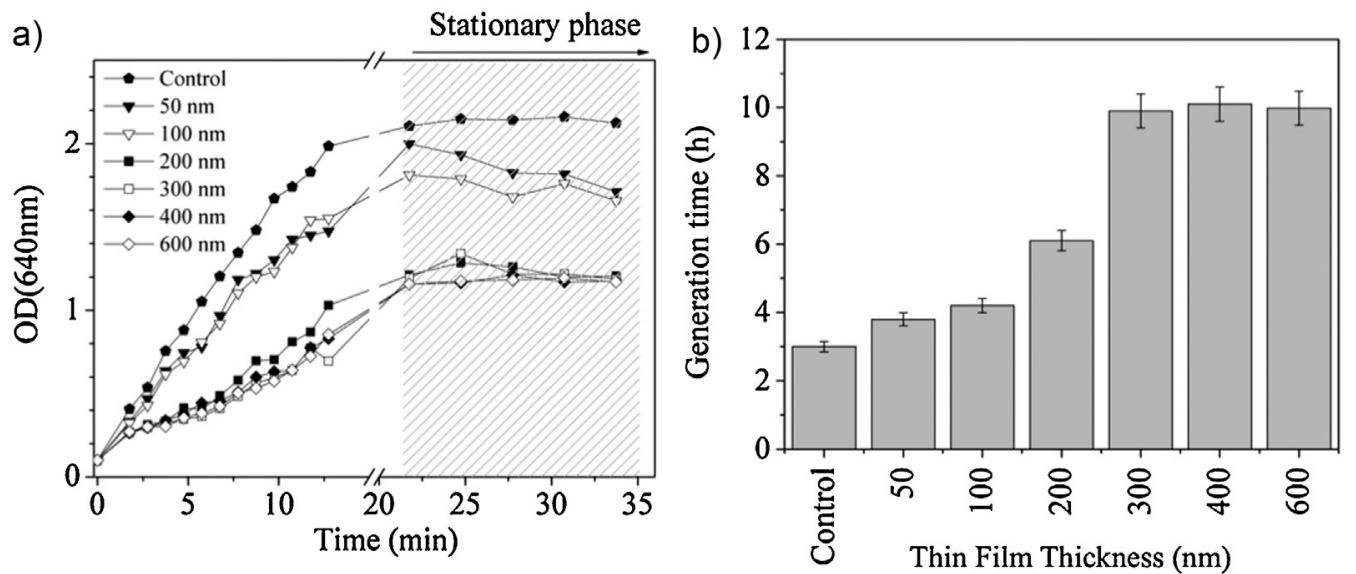

Fig. 5. Antibacterial activity of the ZnO thin films against E. coli. (a) Bacteria cells were incubated with thin films with different thickness and growth monitored over time measuring OD at $640 \mathrm{~nm}$. The control growth was assessed using non-coated PET with the same area. (b) Influence of thin film thickness on bacteria generation time.

important to point out that the thickest coating $(200-600 \mathrm{~nm})$ not only increase the generation time, i.e. decrease of the growth rate, (Fig. 5b)), but also decreased in $45 \%$ the amount of bacteria cells present at the end of the experiment. This characteristic is important for food packaging applications since it clearly reduces bacterial load.

The thin films having thicknesses of $50-100 \mathrm{~nm}$ present an increase of generation time by a factor of 1.26 and 1.4, respectively. By another hand, the thin films with $200-600 \mathrm{~nm}$ induced an increase by a factor from 2 to 3.3, in comparison with the control (Fig. 5b). It can also be observed that samples with thicknesses higher than $200 \mathrm{~nm}$ present approximately the same antibacterial activity (Fig. 5b). These results suggest that there exists a maximum thickness above which bacteria growth rate is not further reduced with increasing thickness. In summary, it is possible to conclude that films with $200-600 \mathrm{~nm}$ were the ones with the best performance in what concerns the reduction of bacteria's growth rate and the total number of bacterial cells.

ZnO powder has been used for a long time as an active antibacterial ingredient for dermatological applications such as creams, lotions and ointments [28]. However, $\mathrm{ZnO}$ nanoparticles are much more effective agents in controlling the growth of different microorganisms than micro-powders. Some authors $[29,30]$ have been reporting that the smaller the particle size, the greater the efficiency in inhibiting bacteria growth. Moreover, several works showed that the antimicrobial activity is also dependent of the concentration used [31,32]. The higher the concentration of $\mathrm{ZnO}$ nano/micro particles, the higher the antibacterial effect achieved. These results indicate that increasing the active surface area enhances the antimicrobial activity. This conclusion could explain the initial increase of the antibacterial performance of the zinc oxide coatings observed in our study from coatings with $50-100 \mathrm{~nm}$ to $200-600 \mathrm{~nm}$ (Fig. 5). The contact of moisture in the medium, per unit $\mathrm{ZnO}$ mass, increases with the increase of columns length or coating thickness and with the decrease of coatings density. This initial increase in growth inhibition should result from the increase of the surface area resulting from the increase in columns length (coatings thickness). However, this inhibition effect stabilizes at $200 \mathrm{~nm}$. The posterior stabilization should result from the approximately constant surface area. The active surface area depends on three factors, column length, column width and the percentage of voids between columns that are accessible to the species in the liquid phase. As already discussed in this work, associated with the coatings thickness (columns height) enhancement is an increase in the coatings columns width. The increase of columns width can decrease the percentage of voids between columns that are accessible to the species in the liquid phase, keeping constant the active surface area, i.e. the surface area that is accessible to the species in the liquid phase. The saturation of the active surface area explains the maintenance of the antibacterial performance after stabilization.

After determining the critical thickness of the $\mathrm{ZnO}$ coatings on the antibacterial activity of the films, the influence of the silver dopant content in the final properties of the coatings was also evaluated. For this purpose, a new set of samples was deposited, using a constant thickness of $\sim 200 \mathrm{~nm}$, but having different $\mathrm{Ag} / \mathrm{Zn}$ ratio. $\mathrm{The} \mathrm{Ag} / \mathrm{Zn}$ ratio was increased until the average transmittance value in the visible region ( $\left.T_{\text {vis. }}\right)$ of the coatings decreased to about $80 \%$. Assuming the mentioned restriction $\left(T_{\text {vis }}>80 \%\right)$, three different coatings were obtained. The composition data obtained by X-Ray Photoelectron Spectroscopy (XPS) analysis show that the $\mathrm{Ag} / \mathrm{Zn}$ atomic ratios of the coatings were respectively $0.005(\mathrm{ZnO}(\mathrm{Ag})-1)$, $0.007(\mathrm{ZnO}(\mathrm{Ag})-2)$, and $0.04(\mathrm{ZnO}(\mathrm{Ag})-3)$.

Fig. 6 shows the XRD patterns of undoped and $\mathrm{Ag}$ doped $\mathrm{ZnO}$ thin films having different $\mathrm{Ag} / \mathrm{Zn}$ atomic ratios. From the presented diffraction pattern it can be observed that the only polycrystalline crystalline phase detected corresponds to the $\mathrm{ZnO}$ hexagonal wurtzite type (JPCDS36-1451, $a=0.326 \mathrm{~nm}$ and $c=0.522 \mathrm{~nm}$ ). No phases corresponding to silver or silver oxide were detected, which indicates that there is no additional phase present in the $\mathrm{ZnO}: \mathrm{Ag}$ films (at least within the limit of X-ray detection). The undoped $\mathrm{ZnO}$ sample deposited on Si substrate present similar preferential growth regarding the one deposited on PET substrate, see Fig. 1. The samples $\mathrm{ZnO}(\mathrm{Ag})-1$ and $\mathrm{ZnO}(\mathrm{Ag})-2$ present several major peaks of $\mathrm{ZnO}$, indicating low extend of crystalline preferential growth. This

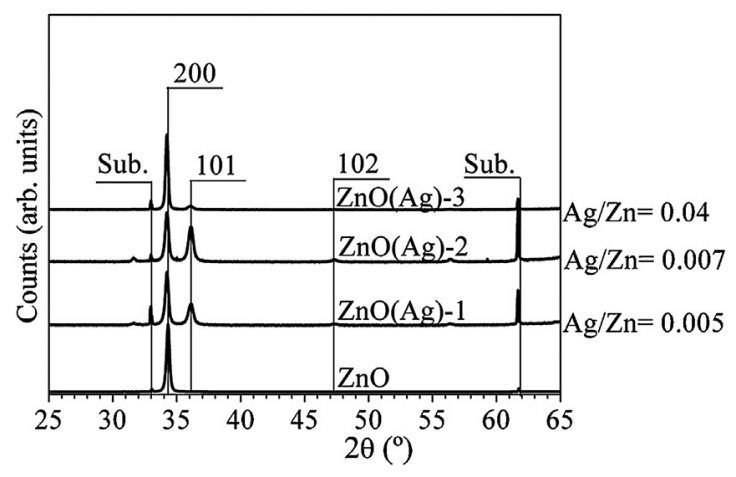

Fig. 6. XRD patterns of silver doped $\mathrm{ZnO}$ thin films. It is also included a non doped $\mathrm{ZnO}$ sample. All coatings were deposited on Si substrate. 


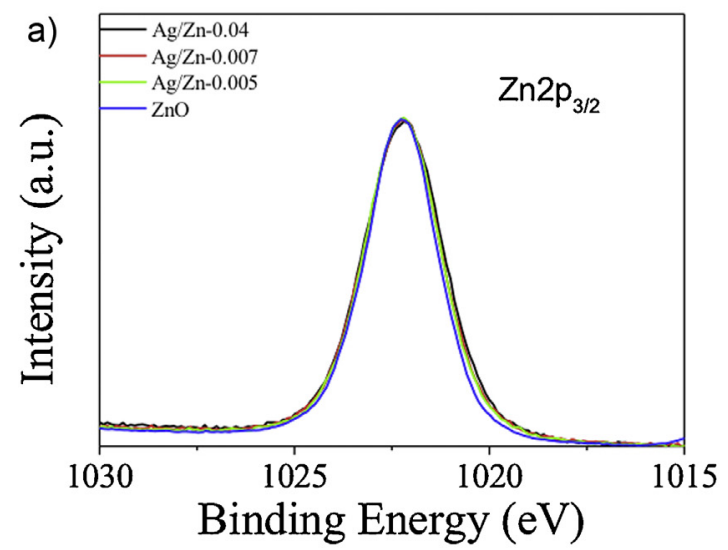

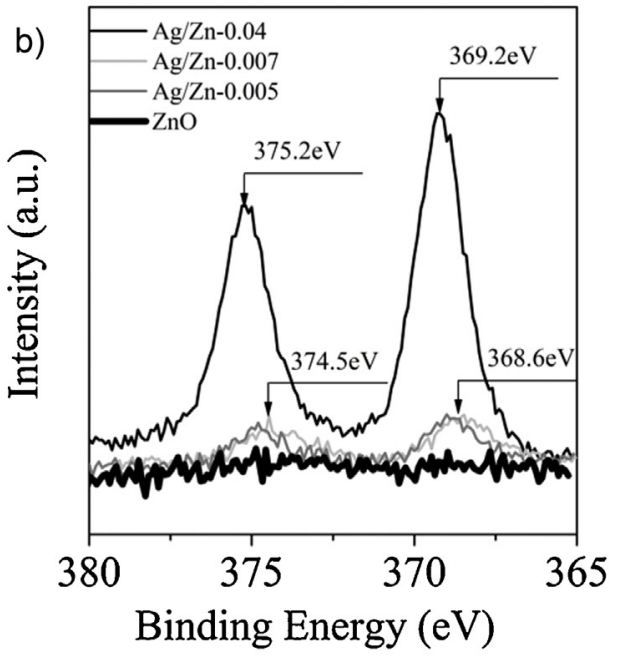

Fig. 7. (a) XPS Zn2 $\mathrm{p}_{3 / 2}$ and (b) Ag3d spectra of silver doped $\mathrm{ZnO}$ films and undoped $\mathrm{ZnO}$.

could indicate that the presence of silver, in very low concentration, may inhibit the c-axis preferential growth of $\mathrm{ZnO}$ films. As for the change of c-orientation with Ag doping, some authors [33,34] detected a decrease in the extent of $c$-orientation while others [35] observed an opposite behaviour by Ag doping. Oleg Lupan et al. [36] proposed that heterogeneous nucleation could be facilitated in the presence of $\mathrm{Ag}^{+}$ions in the $\mathrm{ZnO}$ structure, enhancing the growth rate in the (101) direction.

The sample with the highest concentration of silver, $\mathrm{ZnO}(\mathrm{Ag})-3$, present similar XRD spectrum as the undoped ZnO samples, showing a clear $c$-orientation.

All the Ag doped ZnO films present a small X-Ray Diffraction peak shift as compared with pure $\mathrm{ZnO}$, resulting from the $\mathrm{ZnO}$ lattice parameter increased in the c-axis with $\mathrm{Ag}$ doping. According to literature $[37,38]$ the slight decrease of $2 \theta$ may be due to the increase of its lattice constant caused by substitution of $\mathrm{Zn}^{2+}$ ions (radius of $0.65 \AA$ ) by $\mathrm{Ag}^{+}$ions (radius of $1.02 \AA$ ) leading to the compressive distortion of the crystalline structure. Due to its large ionic radius, Ag+ would preferentially choose to sit in the vicinity of grain boundaries [39]. Based on first-principles calculations, several authors $[40,41]$ indicated the formation energy for Ag-Zn (Ag in substitutional sites) is lower than that for $\mathrm{Ag}-\mathrm{i}$ ( $\mathrm{Ag}$ in interstitial sites). Based on that, if $\mathrm{Ag}+$ ions are available during deposition, it is expected that they may be inserted into $\mathrm{ZnO}$ crystalline structure by substitution of $\mathrm{Zn}^{2+}$ ions, within the solubility limits. Shu-Ting Kuo et al. [39] proposed that the solubility of $\mathrm{Ag}$ in $\mathrm{ZnO}$ is between 0.08 and $0.76 \mathrm{~mol} \%$. The same authors, based on the TEM observations, concluded that for higher concentrations above the Ag solubility limit it tend to segregate at the grain boundaries of $\mathrm{ZnO}$. This small value determined by Shu-Ting Kuo et al. [39] is somehow expected since the large size difference between $\mathrm{Zn}^{2+}$ and $\mathrm{Ag}^{+}$ions should reduce the solubility of $\mathrm{Ag}$ in $\mathrm{ZnO}$ lattice.

Regarding the surface composition of the silver doped $\mathrm{ZnO}$ thin films, Fig. 7 shows the XPS Zn2p and Ag3d spectra.

The $\mathrm{Zn} 2 \mathrm{p} 3 / 2$ core line, (calibrated at $1022.2 \mathrm{eV}$ [42] of binding energy) exhibits a small asymmetry in the right side, in comparison with the signal from pure $\mathrm{ZnO}$, indicating that zinc could present more than one oxidation state. The XPS spectra of $A g 3 d_{3 / 2}$ peak (Fig. 7) show binding energies in the range 368.6-369.2 $\mathrm{eV}$ for the three doped samples. It is well known that the binding energies of silver photoelectron signals decrease with the oxidation state of this element. Thus, the binding energy value of $A g 3 d_{3 / 2}$ peak for $\mathrm{Ag}, \mathrm{Ag}_{2} \mathrm{O}$, and $\mathrm{AgO}$ bulk samples are $368.22,367.8$, and $367.4 \mathrm{eV}$, respectively [43-46]. It is evident that, for the three $\mathrm{Ag}$ doped $\mathrm{ZnO}$ samples whose spectra are depicted in Fig. 7, binding energy is always higher than that expected for bulk Ag or any other reported bulk silver compound, and for the case of the sample with the highest apparent silver content, that one presenting the more intense peaks, this difference with respect to metallic silver is as large as $+1 \mathrm{eV}$.

Two different reasons could be argued to explain the high binding energy values obtained for $\mathrm{Ag}^{3} \mathrm{~d}_{3 / 2}$ peaks in $\mathrm{ZnO}(\mathrm{Ag})$ films. First, that silver is forming nanometric metal clusters, as it has been widely found for this and other metallic elements in the literature [47]. For instance, in comparison with the binding energy of bulk $\mathrm{Ag}$ sample, a shift of $0.4 \mathrm{eV}$ has been observed for nanometric silver particles when they are deposited on graphite [47], shifts of $+0.6 \mathrm{eV}$ [48] or $+0.9 \mathrm{eV}$ [49] when dispersed on $\mathrm{Al}_{2} \mathrm{O}_{3}$, and shifts of +0.6 or $+1.2 \mathrm{eV}$ when supported on $\mathrm{TiO}_{2}$ at $300 \mathrm{~K}$ or $100 \mathrm{~K}$, respectively [49]. These shifts have been attributed to both initial and final state factors affecting the photoemission process, as for instance, the metal-substrate interaction, the mean coordination of the atoms in the clusters and their geometry $[47,50]$. Final state effects are those affecting the Coulomb potential or the dielectric constant of the substrates [51,52]. The binding energy shift observed in our samples, up to $+1.0 \mathrm{eV}$, would be in the upper limit of the range found for small silver clusters on $\mathrm{Al}_{2} \mathrm{O}_{3}$ and $\mathrm{TiO}_{2}$. To verify the validity of this hypothesis, we have carried out an experiment where increasing amounts of pure silver are condensed under ultra high vacuum on $\mathrm{ZnO}$ films, from a fraction of a monolayer to several tens of monolayers. Note that, regardless of the growth mechanism followed by silver depositing on $\mathrm{ZnO}$ (layer by layer or three dimensional island growth), the mean particle sizes will increases when the deposited amount increases. The result of this experiment is illustrated in Fig. 8, where the evolution of the $A g 3 d_{5 / 2}$ peak binding energy is ploted versus the nominal thickness of deposited silver. As can be observed, when deposited on $\mathrm{ZnO}$, the binding energy of very small silver aggregates only shift up to $+0.6 \mathrm{eV}$ in respect to that one of bulk silver, which is quite lower than the experimental value found for $\mathrm{Ag}$ doped $\mathrm{ZnO}$ films.

A second possible hypothesis to explain the high binding energy found for $\mathrm{Ag}$ doped $\mathrm{ZnO}$ films, is that the noble metal particles are doped with $\mathrm{Zn}$, giving rise to the formation of an intermetallic compound, as reported for $\mathrm{AlAg}_{2}$, which binding energy, $368.7 \mathrm{eV}$, is also higher than that for bulk silver [53]. Since the percentage of silver doping the $\mathrm{ZnO}$ films is very low, the detection of the $\mathrm{Zn}$ species linked to the silver atoms is fully hidden by those $\mathrm{Zn}$ atoms located in the $\mathrm{ZnO}$ phase. Moreover, metal $\mathrm{Zn}$ species cannot be 


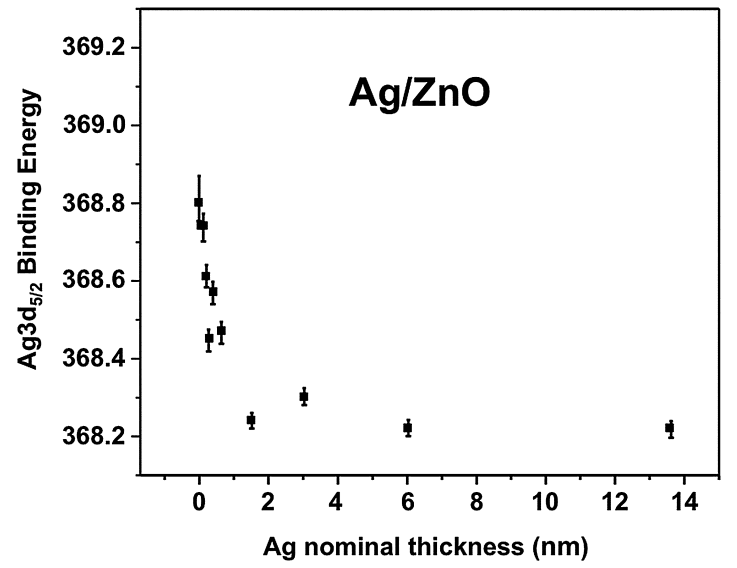

Fig. 8. Evolution of the $\mathrm{Ag} 3 \mathrm{~d}_{5 / 2}$ binding energy for deposits of silver on $\mathrm{ZnO}$ as a function of the nominal thickness of deposited silver (in $\mathrm{nm}$ ).

distinguished from $\mathrm{Zn}^{+2}$ cations by XPS on the basis of the main primary photoelectron signals (Zn2p), because both chemical species generate just the very same spectrum. Fortunately, the elucidation of the chemical state of $\mathrm{Zn}$ can be made effectively by XPS by determining the value of the modified Auger parameter [54], $\alpha^{\prime}$, which is equal to the sum of the binding energy of the $Z n 2 p_{3 / 2}$ photoelectron peak and the kinetic energy of the $\mathrm{Zn}_{\mathrm{L3M} 45 \mathrm{M} 45}$ Auger line.

In order to further study this second hypothesis, a film of $\mathrm{Zn}$ containing a small amount of $\mathrm{Ag}$, was deposited by magnetron sputtering from $\mathrm{Zn}$ and $\mathrm{Ag}$ targets. This film, when examined by XPS, only showed divalent zinc at the surface, characterized by a modified Auger parameter of $\sim 2010.0 \mathrm{eV}$, very likely as a consequence of the corrosion of this metal during its exposition to the atmosphere of the laboratory. However, and as expected, the sputtering cleaning of its surface by ion bombardment gradually removes the altered layer, and a stationary state is reached in its composition after removal of around $\sim 12 \mathrm{~nm}$. The evolution of the surface composition of this film by the ion etching treatment is neatly noticeable by the decrease in the $\mathrm{O} / \mathrm{Zn}$ atomic ratio and by

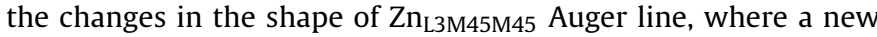
peak at $991.8 \mathrm{eV}$ of kinetic energy, due to $\mathrm{Zn}(0)$, rises with the sputtering treatment. In Fig. 9, the spectral region for $\mathrm{Zn}_{\mathrm{L3M} 45 \mathrm{M} 45}$ signal is shown for this sample at the stationary state, where the peaks

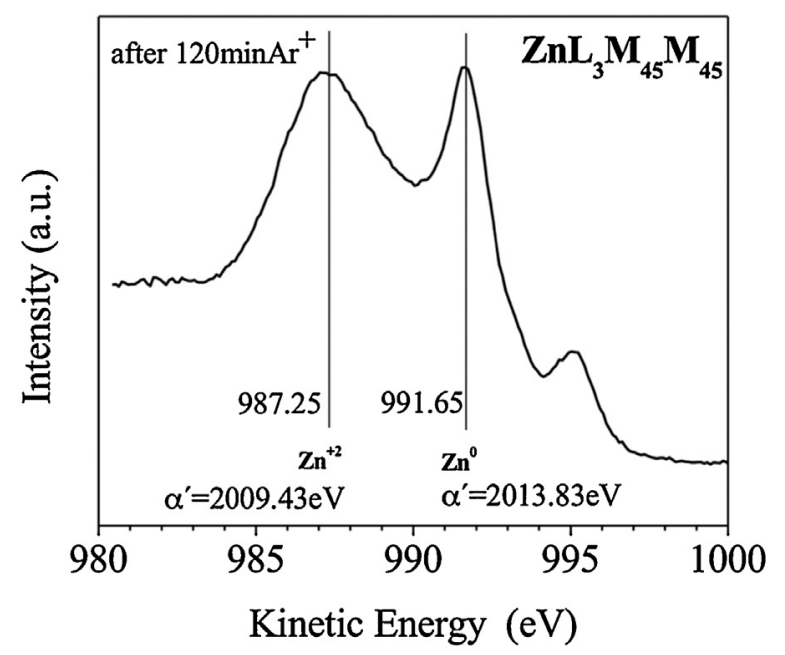

Fig. 9. Photoemission spectrum of the $\mathrm{Zn}_{\mathrm{L3M} 45 \mathrm{M} 45}$ Auger line for the $\mathrm{Zn}(\mathrm{Ag})$ sample after surface cleaning by sputtering with $\mathrm{Ar}^{+}$ions of $2.5 \mathrm{keV}$ for $120 \mathrm{~min}$. for $\mathrm{Zn}(0)$ and $\mathrm{Zn}(+2)$ are labelled and the values of the respective modified Auger parameters calculated.

Fig. 10 shows the $Z n 2 p_{3 / 2}$ and $A g 3 d$ photoemission signals of this silver doped zinc film at the original state (surface corroded) and after a long sputtering treatment. As can be seen, the intensities of both $\mathrm{Zn}$ and Ag signals increase with this treatment, as a result of the removal of surface contaminants and, very likely, the preferential sputtering of oxygen. On the other hand, $\mathrm{Ag} 3 \mathrm{~d}_{5 / 2}$ peak shifts with the sputtering treatment from 368.64 to $369.47 \mathrm{eV}$, as expected for the formation of a $\mathrm{Zn}-\mathrm{Ag}$ alloy. Note that this final binding energy value is so high that it cannot be ascribed to pure nanometric silver particles.

In summary, while the presence of very small aggregates of silver (first hypothesis) could only account for a binding energy shift of up to $+0.6 \mathrm{eV}$, the doping of these particles with $\mathrm{Zn}$ (second hypothesis) could explain by itself the whole experimental shift and even further.

Fig. 11 shows the top and cross section micrographs of the silver doped $\mathrm{ZnO}$ thin films.

From the previous figure it is possible to observe that the presence of silver induces a change in the $\mathrm{ZnO}$ coatings morphology in comparison with Fig. $2 \mathrm{~b}$. For the samples with very low silver content, $\mathrm{ZnO}(\mathrm{Ag})-1$ and 2 (not showed here), the shape of the columns change from circular pillar-like morphology (see Fig. 2) to triangular morphology (see Fig. 11), maintaining a $\mathbf{V}$ shape form in the cross section view. It is important to note that these samples do not show a crystalline preferential growth, in contrast with the undoped zinc oxide samples. The sample with the highest silver content presents a columnar morphology with a circular shape, similar to the undoped samples, but with a much less dense morphology, where the space between columns is cleared observed. Once more time, the circular columnar morphology is related to a preferential orientation of the c-axis perpendicular to the substrate surface (see Fig. 6). This result suggests that the different crystalline growth related with the presence of silver could induce morphology changes in the coatings. Wang et al. [55] reported that Ag doping could cause morphological changes in the $\mathrm{ZnO}$ thin films. The authors observed that the presence of silver induces the formation of a porous morphology.

The antibacterial activities of undoped and $\mathrm{Ag}$-doped $\mathrm{ZnO}$ thin films against $E$. coli are depicted in Fig. 12.

From the previous plot (Fig. 12) it is possible to observe an enhancement of antibacterial activity with the increase of silver content in the zinc oxide based coatings. With the increase of silver content there is a decrease of $E$. coli growth rate (see, Fig. 12a and $b$ ), a decreased amount of bacteria cells present at the end of the experiment. On the other hand for the sample having the highest $\mathrm{Ag} / \mathrm{Zn}$ atomic ratio of 0.04 it is observed a complete growth inhibition (see, Fig. 12a).

The antibacterial mechanism of $\mathrm{ZnO}$ is still under investigation. Two major mechanisms have been suggested: (1) the release of $\mathrm{Zn}^{2+}$ ions from the coating [56] and (2) the generation of hydrogen peroxide as well as radical oxygen species from $\mathrm{ZnO}$ surface $[57,58]$.

Sugarman [59] suggested that zinc ions bind to the membranes of microorganisms, extending the lag phase of the growth cycle and increasing the generation time of the microorganisms [60]. Others authors $[28,61,62]$, observed that $\mathrm{Zn}^{2+}$ ions do not have much antibacterial activity up to a concentration of $7.3 \times 10^{-5} \mathrm{M}$, the same order of magnitude of the solubility of $\mathrm{ZnO}$ in the solution. This may be consistent with the prediction that $E$. coli can metabolize $\mathrm{Zn}^{2+}$ as an oligoelement [63]. This suggests that these ions are not primarily responsible for the antibacterial activity of $\mathrm{ZnO}$. The same authors claimed that the antimicrobial dominant mechanism should result from Radical Oxygen Species (ROS) generation and their subsequent interaction with cell. 

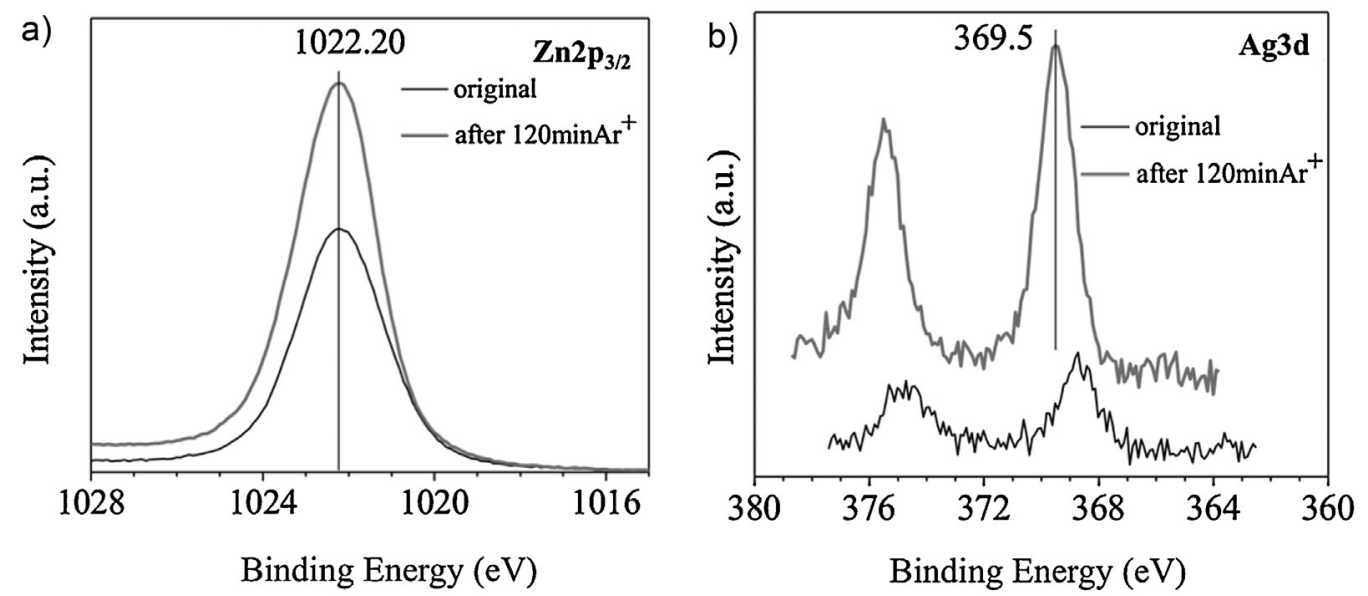

Fig. 10. XPS Zn2 $\left.\mathrm{p}_{3 / 2}(\mathrm{a})\right)$ and $\left.\mathrm{Ag} 3 \mathrm{~d}(\mathrm{~b})\right)$ spectra of silver doped zinc thin film at the original state and after 120 min of surface etching with $\mathrm{Ar}^{+}$ions of $2.5 \mathrm{keV}$.

Regarding the generation of highly reactive species, such as $\mathrm{OH}^{\bullet}$ radicals, $\mathrm{H}_{2} \mathrm{O}_{2}$ and ${ }^{\circ} \mathrm{O}_{2}{ }^{2-}$, Padmavathy et al. [64] explained as follows: $\mathrm{ZnO}$ with defects can be activated by both UV and visible light, which will induce electron-hole pairs $\left(\mathrm{e}^{-} / \mathrm{h}^{+}\right)$generation. Water molecules can spontaneously dissociate into $\mathrm{OH}^{-}$and $\mathrm{H}_{3} \mathrm{O}^{+}$species. Dissolved oxygen molecules are transformed to superoxide radical anions ${ }^{\bullet} \mathrm{O}_{2}^{-}$, that in turn will react with $\mathrm{H}_{3} \mathrm{O}^{+}$to generate $\left(\mathrm{HO}_{2}{ }^{\bullet}\right)$ radicals, which upon subsequent collision with electrons produce
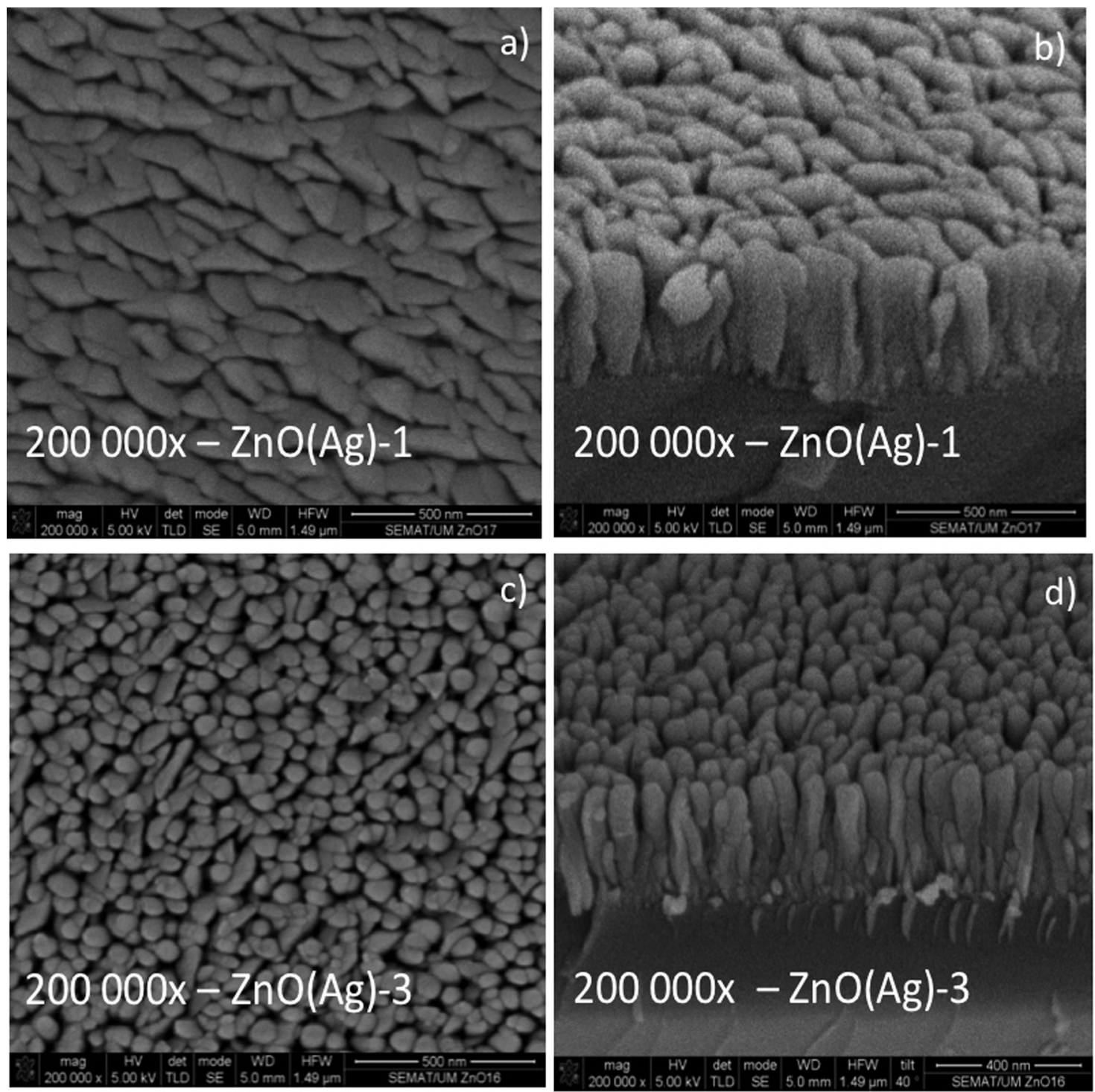

Fig. 11. Top-view and cross section SEM micrographs of silver doped $\mathrm{ZnO}$ thin films; (a and b) $\mathrm{ZnO}(\mathrm{Ag})-1 \mathrm{sample}$, (c and d) $\mathrm{ZnO}(\mathrm{Ag})-3$ sample. 
a)

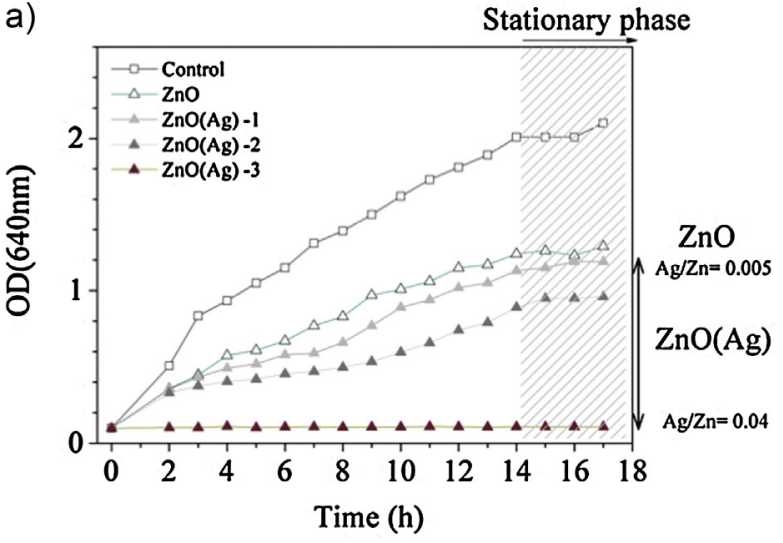

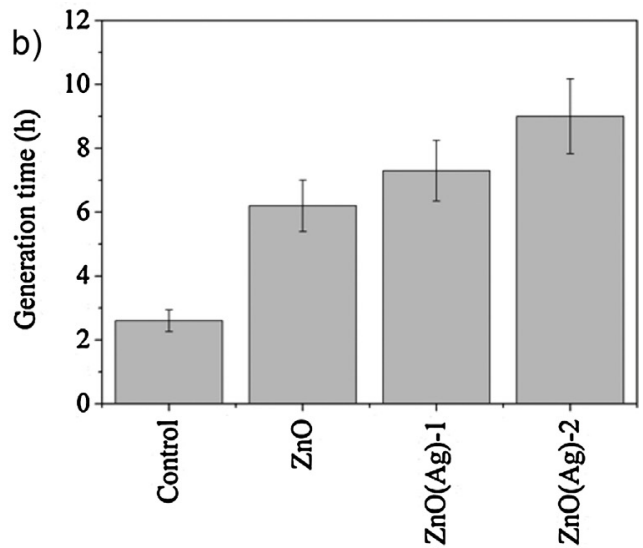

Fig. 12. Antibacterial activities of undoped and Ag- doped $\mathrm{ZnO}$ thin films against E. coli. (a) Optical density (OD) at $640 \mathrm{~nm}$ over time of incubated bacteria cells with different $\mathrm{Ag}$ content. The control growth was assessed using non coated PET with the same area; (b) generation time of $E$. coli bacteria.

hydrogen peroxide anions $\left(\mathrm{HO}_{2}{ }^{-}\right)$. Then, they then react with $\mathrm{H}_{3} \mathrm{O}^{+}$ to produce $\mathrm{H}_{2} \mathrm{O}_{2}$ molecules. However, light is needed to produce photocatalytic ROS. Since in the present work the E. coli bacteria cells were incubated in dark conditions, the generation of (ROS) cannot be explained by a photocatalytic mechanism. By another hand, Hirota et al. [65] and Sawai et al. [66] observed the generation of $\bullet \mathrm{OH}$ radicals from $\mathrm{ZnO}$ ceramics in dark conditions. Both authors did not explain the formation mechanism of these radicals.

Regarding the silver antimicrobial activity, silver cation $\left(\mathrm{Ag}^{+}\right)$ is highly reactive since it binds strongly to electron donor groups containing sulphur, oxygen or nitrogen [67], but metallic silver has only slight antibacterial effects because it is chemically stable [67]. Biological molecules usually contain these components in the form of thiol, amino, imidazole, carboxylate and phosphate groups. The bonding of silver ions to bacterial deoxyribonucleic acid (DNA) [68] may inhibit a number of important transport processes, such as phosphate and succinate uptake and can interact with cellular oxidation processes as well as the respiratory chain [67]. It was also shown that $\mathrm{Ag}+$ bonds to functional groups of proteins resulting its denaturation [69]. It is also supposed that DNA loses its replication ability and cellular proteins become inactivated on $\mathrm{Ag}^{+}$treatment [70]. Concerning to our specific results, some questions still remain to $t$ be answered. They are related with the chemical activity of silver that enhances the antimicrobial effect or its influence in the coatings morphology that induces an increase of the antimicrobial effect. As shown in this work, the coatings morphology was greatly influenced the antimicrobial performance of the coatings and the presence of silver strongly changes the active surface area of the coatings. Further studies will be performed to clarify these questions.

\section{Conclusions}

ZnO thin films, with thickness varying from 50 to $600 \mathrm{~nm}$, were prepared by using DC Reactive Magnetron Sputtering. Silver doped Zinc Oxide thin films $(\mathrm{ZnO}(\mathrm{Ag}))$ with different silver content and thicknesses closed to $200 \mathrm{~nm}$ were also produced. All the deposited zinc oxide and silver doped $\mathrm{ZnO}$ coatings present a columnar morphology with $\mathrm{V}$-shaped columns. The increase of coatings thickness until $200 \mathrm{~nm}$ increases the active surface area of the columns whereas further increasing the thickness induces a decrease of the ratio of the columns surface area and columns length. This results in a saturation of the active surface area of the thin films. All the ZnO based thin films present a hexagonal wurtzite type (JPCDS36-1451) and no additional phases of to silver or silver oxides were detected in the doped samples. The XRD results reveal that $\mathrm{Ag}^{+}$should substitute $\mathrm{Zn}^{2+}$ ions in the zinc oxide matrix leading to a distortion of the crystalline structure. XPS analysis revealed high values of binding energy of $\mathrm{Ag} 3 \mathrm{~d}$ indicating a possible formation of a $\mathrm{Zn}$ $\mathrm{Ag}$ bond in the zinc oxide coatings. In the case of antimicrobial properties, thin films with 50 to $100 \mathrm{~nm}$ present an increase of generation time by a factor of 1.26 and 1.4 , respectively. By another hand the thin films with $200 \mathrm{~nm}$ to $600 \mathrm{~nm}$ induced an increase of the generation time by a factor from 2 to 3.3. The thickest coating $(200-600 \mathrm{~nm})$ showed a reduction in the number of bacterial cells at the end of the experience, that was $45 \%$ at the stationary phase. This characteristic is extremely important for food packaging applications because it may reduce bacterial load. Ag-doping of $\mathrm{ZnO}$ enhances their antibacterial activities. In fact, with the increase of silver content there exists a decrease of $E$. coli growth rate and a decreased of the amount of bacteria cells present at the end of the experiment (until a complete growth inhibition for the sample with a $\mathrm{Ag} / \mathrm{Zn}$ atomic ratio of 0.04 ).

\section{Acknowledgements}

The work described in this paper was supported by project NANOPACKSAFER: NANO-engineered PACKaging systems for improving quality, SAFEty and health characteristics of foods, Portugal-Spain International Nanotechnology Laboratory Nanotechnology Projects Call; and also by the FEDER funding through the COMPETE program and FCT PEst-C/BIA/UI4050/2011 project.

\section{References}

[1] J. Greig, E. Todd, C. Bartleson, B. Michaels, Outbreaks where food workers have been implicated in the spread of foodborne disease. Part 1. Description of the problem, methods, and agents involved, J. Food Prot. 70 (2007) 1752-1761.

[2] D. Vugia, A. Cronquist, J. Hadler, M. Tobin-D’Angelo, D. Blythe, K. Smith, et al., Preliminary FoodNet Data on the incidence of infection with pathogens transmitted commonly through food - 10 states, 2007, Morb. Mortal. Wkly. Rep. 2 (2008) 114.

[3] D. Davies, Understanding biofilm resistance to antibacterial agents, Nat. Rev. Drug Discov. 2 (2003) 114-122.

[4] U. Desselberger, Emerging and re-emerging infectious diseases, J. Infect. 40 (2000) 3-15.

[5] R. Villalobos, P. Hernández-Muñoz, A. Chiralt, Effect of surfactants on water sorption and barrier properties of hydroxypropyl methylcellulose films, Food Hydrocoll. 20 (2006) 502-509.

[6] I. Sondi, B. Salopek-Sondi, Silver nanoparticles as antimicrobial agent: a case study on E. coli as a model for Gram-negative bacteria, J. Colloid Interface Sci. 275 (2004) 177-182.

[7] T. Maneerung, S. Tokura, R. Rujiravanit, Impregnation of silver nanoparticles into bacterial cellulose for antimicrobial wound dressing, Carbohydr. Polym. 72 (2008) 43-51.

[8] O. Yamamoto, Influence of particle size on the antibacterial activity of zinc oxide, Int. J. Inorg. Mater. 3 (2001) 643-646. 
[9] V. Thati, A.S. Roy, M.V.N.A. Prasad, C.T. Shivannavar, S.M. Gaddad, Nanostructured zinc oxide enhances the activity of antibiotics against Staphylococcus aureus, J. Biosci. Technol. 1 (2010) 64-69.

[10] V. a Yadav, A.A. Prasad, S. Kathe, D. Raj, C. Yadav, Sundaramoorthy, et al., Functional finishing in cotton fabrics using zinc oxide nanoparticles, Bull. Mater. Sci. 29 (2006) 641-645

[11] S.M. Hussain, K.L. Hess, J.M. Gearhart, K.T. Geiss, J.J. Schlager, In vitro toxicity of nanoparticles in BRL 3A rat liver cells, Toxicol. In Vitro 19 (2005) 975-983.

[12] T.R. Pisanic, J.D. Blackwell, V.I. Shubayev, R.R. Fiñones, S. Jin, Nanotoxicity of iron oxide nanoparticle internalization in growing neurons, Biomaterials 28 (2007) 2572-2581.

[13] A. Fujishima, T.N. Rao, D.A. Tryk, Titanium dioxide photocatalysis, J. Photochem. Photobiol. C: Photochem. Rev. 1 (2000) 1-21.

[14] C.-J. Chung, H.-I. Lin, H.-K. Tsou, Z.-Y. Shi, J.-L. He, An antimicrobial TiO 2 coating for reducing hospital-acquired infection, J. Biomed. Mater. Res. B: Appl. Biomater. 85 (2008) 220-224.

[15] J. Fahlteich, M. Fahland, W. Schönberger, N. Schiller, Permeation barrier properties of thin oxide films on flexible polymer substrates, Thin Solid Films 517 (2009) 3075-3080.

[16] J.O. Carneiro, V. Teixeira, A. Portinha, A. Magalhães, P. Coutinho, C.J. Tavares, et al., Iron-doped photocatalytic $\mathrm{TiO}_{2}$ sputtered coatings on plastics for selfcleaning applications, Mater. Sci. Eng. B 138 (2007) 144-150.

[17] American Society for Testing and Materials, Powder Diffraction Files, in: Joint Committee on Powder Diffraction Standards, Swarthmore, PA, 1999, pp. 3-888.

[18] Y. Yang, X.W. Sun, B.J. Chen, C.X. Xu, T.P. Chen, C.Q. Sun, et al., Refractive indices of textured indium tin oxide and zinc oxide thin films, Thin Solid Films 510 (2006) 95-101.

[19] D. Klaitabtim, S. Pratontep, J. Nukeaw, Effect of gas-timing technique on structure and optical properties of sputtered zinc oxide films, Ceram. Int. 34 (2008) 1103-1107.

[20] N. Fujimura, T. Nishihara, S. Goto, J. Xu, T. Ito, Control of preferred orientation for $\mathrm{ZnO}_{x}$ films: control of self-texture, J. Cryst. Growth 130 (1993) 269-279.

[21] D. Bao, H. Gu, A. Kuang, Sol-gel-derived c-axis oriented ZnO thin films, Thin Solid Films 312 (1998) 37-39.

[22] S. Amirhaghi, V. Craciun, D. Craciun, J. Elders, I.W. Boyd, Low temperature growth of highly transparent $c$-axis oriented $\mathrm{ZnO}$ thin films by pulsed laser deposition, Microelectron. Eng. 25 (1994) 321-326.

[23] E. Mirica, G. Kowach, H. Du, Modified structure zone model to describe the morphological evolution of $\mathrm{ZnO}$ thin films deposited by reactive sputtering, Cryst. Growth Des. 4 (2004) 157-159.

[24] J.W. Shin, J.Y. Lee, T.W. Kim, Y.S. No, W.J. Cho, W.K. Choi, Growth mechanisms of thin-film columnar structures in zinc oxide on p-type silicon substrates, Appl. Phys. Lett. 88 (2006) 091911

[25] A. van der Drift, Evolutionary selection, a principle governing growth orientation in vapour-deposited layers, Philips Res. Rep. 22 (1967) 267-288.

[26] G. Knuyt, C. Quaeyhaegens, J. D'Haen, L.M. Stals, A quantitative model for the evolution from random orientation to a unique texture in PVD thin film growth, Thin Solid Films 258 (1995) 159-169.

[27] Y.-J. Jeon, S.-K. Kim, Production of chitooligosaccharides using an ultrafiltration membrane reactor and their antibacterial activity, Carbohydr. Polym. 41 (2000) 133-141.

[28] J. Sawai, Quantitative evaluation of antibacterial activities of metallic oxide powders ( $\mathrm{ZnO}, \mathrm{MgO}$ and $\mathrm{CaO}$ ) by conductimetric assay, J. Microbiol. Methods 54 (2003) 177-182.

[29] N. Jones, B. Ray, K.T. Ranjit, A.C. Manna, Antibacterial activity of ZnO nanoparticle suspensions on a broad spectrum of microorganisms, FEMS Microbiol. Lett. 279 (2008) 71-76

[30] S. Nair, A.V. Sasidharan, V. Divya Rani, D. Menon, S. Nair, K. Manzoor, et al., Role of size scale of ZnO nanoparticles and microparticles on toxicity toward bacteria and osteoblast cancer cells, J. Mater. Sci. Mater. Med. 20 (Suppl. 1) (2009) S235-S241.

[31] T. Jin, D. Sun, J.Y. Su, H. Zhang, H.-J. Sue, Antimicrobial efficacy of zinc oxide quantum dots against Listeria monocytogenes, Salmonella enteritidis, and Escherichia coli O157:H7, J. Food Sci. 74 (2009) M46-M52.

[32] J.H. Li, R.Y. Hong, M.Y. Li, H.Z. Li, Y. Zheng, J. Ding, Effects of ZnO nanoparticles on the mechanical and antibacterial properties of polyurethane coatings, Prog. Org. Coat. 64 (2009) 504-509.

[33] L. Duan, B. Lin, W. Zhang, S. Zhong, Z. Fu, Enhancement of ultraviolet emissions from ZnO films by Ag doping, Appl. Phys. Lett. 88 (2006) 232110.

[34] D.R. Sahu, Properties of doped ZnO thin films grown by simultaneous dc and RF magnetron sputtering, Mater. Sci. Eng. B 171 (2010) 99-103.

[35] D.R. Sahu, Studies on the properties of sputter-deposited Ag-doped ZnO films, Microelectron. J. 38 (2007) 1252-1256.

[36] O. Lupan, L. Chow, L.K. Ono, B.R. Cuenya, G. Chai, H. Khallaf, et al., Synthesis and characterization of Ag- or Sb-doped $\mathrm{ZnO}$ nanorods by a facile hydrothermal route, J. Phys. Chem. C 114 (2010) 12401-12408.

[37] Y. Chen, X.L. Xu, G.H. Zhang, H. Xue, S.Y. Ma, A comparative study of the microstructures and optical properties of $\mathrm{Cu}$ - and $\mathrm{Ag}$-doped $\mathrm{ZnO}$ thin films, Phys. B: Condens. Matter. 404 (2009) 3645-3649.

[38] E. Rita, U. Wahl, A.M.L. Lopes, J.P. Araújo, J.G. Correia, E. Alves, et al., Lattice site and stability of implanted Ag in ZnO, Phys. B: Condens. Matter. 340-342 (2003) 240-244.
[39] S.-T. Kuo, W.-H. Tuan, J. Shieh, S.-F. Wang, Effect of Ag on the microstructure and electrical properties of ZnO, J. Eur. Ceram. Soc. 27 (2007) 4521-4527.

[40] Y. Yan, M.M. Al-Jassim, S.-H. Wei, Doping of ZnO by group-IB elements, Appl. Phys. Lett. 89 (2006) 181912-181914.

[41] Q. Wan, Z. Xiong, J. Dai, J. Rao, F. Jiang, First-principles study of Ag-based p-type doping difficulty in ZnO, Opt. Mater. (Amst.) 30 (2008) 817-821.

[42] M.N. Islam, T.B. Ghosh, K.L. Chopra, H.N. Acharya, XPS and X-ray diffraction studies of aluminum-doped zinc oxide transparent conducting films, Thin Solid Films 280 (1996) 20-25.

[43] A. Boronin, S. Koscheev, G. Zhidomirov, XPS and UPS study of oxygen states on silver, J. Electron. Spectrosc. Relat. Phenom. 96 (1998) 43-51.

[44] S.W. Gaarenstroom, N. Winograd, Initial and final state effects in ESCA spectra of cadmium and silver oxides, J. Chem. Phys. 67 (1977) 3500-3506.

[45] Y. Chiu, U. Rambabu, M.-H. Hsu, H.-P.D. Shieh, C.-Y. Chen, H.-H. Lin, Fabrication and nonlinear optical properties of nanoparticle silver oxide films, J. Appl. Phys. 94 (2003) 1996

[46] W.A. Parkhurst, S. Dallek, B.F. Larrick, Thermogravimetry-evolved gas analysis of silver oxide cathode material, J. Electrochem. Soc. 131 (1984) 1739-1742.

[47] M.G. Mason, Electronic structure of supported small metal clusters, Phys. Rev. B 27 (1983) 748-762.

[48] A. Rodriguez, M. Kuhn, J. Hrbek, Interaction of silver, cesium, and zinc with alumina surfaces: thermal desorption and photoemission studies, J. Phys. Chem. 3654 (1997) 18240-18248.

[49] K. Luo, T.P. St Clair, X. Lai, D.W. Goodman, T.P. St Clair, Silver growth on $\mathrm{TiO}_{2}(110)(1 \times 1)$ and $(1 \times 2) \dagger$, J. Phys. Chem. B $104(2000) 3050-3057$.

[50] P.S. Bagus, C.R. Brundle, G. Pacchioni, F. Parmigiani, Mechanisms responsible for the shifts of core-level binding energies between surface and bulk atoms of metals, Surf. Sci. Rep. 19 (1993) 265-283.

[51] G.K. Wertheim, S.B. DiCenzo, D.N.E. Buchanan, Noble- and transition-metal clusters: the d bands of silver and palladium, Phys. Rev. B 33 (1986) 5384-5390.

[52] J. Egelhoff, F. William, G.G. Tibbetts, Growth of copper, nickel, and palladinm films on graphite and-amorphous carbon, Phys. Rev. B 19 (1979) 5028-5036.

[53] J.C. Fuggle, E. Kallne, L.M. Watson, D.J. Fabian, Electronic structure of aluminum and aluminum - noble-metal alloys studied by soft-X-ray and X-ray photoelectron spectroscopies, Phys. Rev. B 16 (1977) 750-761.

[54] C.D. Wagner, Chemical Shifts of Auger Lines, and the Auger Parameter, Faraday Discuss. Chem. Soc. 60 (1975) 291-300.

[55] L.N. Wang, L.Z. Hu, H.Q. Zhang, Y. Qiu, Y. Lang, G.Q. Liu, et al., Studying the Raman spectra of Ag doped ZnO films grown by PLD, Mater. Sci. Semicond. Process. 14 (2011) 274-277

[56] M. Heinlaan, A. Ivask, I. Blinova, H.-C. Dubourguier, A. Kahru, Toxicity of nanosized and bulk $\mathrm{ZnO}, \mathrm{CuO}$ and $\mathrm{TiO} 2$ to bacteria Vibrio fischeri and crustaceans Daphnia magna and Thamnocephalus platyurus, Chemosphere 71 (2008) 1308-1316.

[57] J. Sawai, S. Shoji, H. Igarashi, A. Hashimoto, T. Kokugan, M. Shimizu, et al., Hydrogen peroxide as an antibacterial factor in zinc oxide powder slurry, J. Ferment. Bioeng. 86 (1998) 521-522.

[58] R. Brayner, R. Ferrari-Iliou, N. Brivois, S. Djediat, M.F. Benedetti, F. Fiévet, Toxicological impact studies based on Escherichia coli bacteria in ultrafine $\mathrm{ZnO}$ nanoparticles colloidal medium, Nano Lett. 6 (2006) 866-870.

[59] B. Sugarman, Zinc and infection, Rev. Infect. Dis. 5 (1983) 137-147.

[60] L.L. Radke, B.L. Hahn, D.K. Wagner, P.G. Sohnle, Effect of abscess fluid supernatants on the kinetics of Candida albicans growth, Clin. Immunol. Immunopathol. 73 (1994) 344-349.

[61] L. Zhang, Y. Jiang, Y. Ding, N. Daskalakis, L. Jeuken, M. Povey, et al., Mechanistic investigation into antibacterial behaviour of suspensions of $\mathrm{ZnO}$ nanoparticles against E. coli, J. Nanoparticle Res. 12 (2009) 1625-1636.

[62] G. Applerot, A. Lipovsky, R. Dror, N. Perkas, Y. Nitzan, R. Lubart, et al., Enhanced antibacterial activity of nanocrystalline $\mathrm{ZnO}$ due to increased ROS-mediated cell injury, Adv. Funct. Mater. 19 (2009) 842-852.

[63] M. Roselli, A. Finamore, I. Garaguso, M.S. Britti, E. Mengheri, Biochemical and molecular actions of nutrients: zinc oxide protects cultured enterocytes from the damage induced by Escherichia coli, J. Nutr. 133 (2003) 4077-4082.

[64] N. Padmavathy, R. Vijayaraghavan, Enhanced bioactivity of ZnO nanoparticles-an antimicrobial study, Sci. Technol. Adv. Mater. 9 (2008) 035004.

[65] K. Hirota, M. Sugimoto, M. Kato, K. Tsukagoshi, T. Tanigawa, H. Sugimoto, Preparation of zinc oxide ceramics with a sustainable antibacterial activity under dark conditions, Ceram. Int. 36 (2010) 497-506.

[66] J. Sawai, E. Kawada, F. Kanou, H. Igarashi, A. Hashimoto, T. Kokugan, et al., Detection of active oxygen generated from ceramic powders having antibacterial activity, J. Chem. Eng. Jpn. 29 (1996) 627-633.

[67] J.M. Schierholz, L.J. Lucas, A. Rump, G. Pulverer, Efficacy of silver-coated medical devices, J. Hosp. Infect. 40 (1998) 257-262.

[68] S.M. Modak, C.L. Fox, Binding of silver sulfadiazine to the cellular components of Pseudomonas aeruginosa, Biochem. Pharmacol. 22 (1973) 2391-2404.

[69] J.A. Spadaro, T.J. Berget, S.D. Barranco, S.E. Chapin, R.O. Becker, Antibacterial effects of silver electrodes with weak direct-current, Antimicrob. Agents Chemother. 6 (1973) 637-642.

[70] O.L. Feng, J. Wu, G.O. Chen, F.Z. Cui, T.N. Kim, J.O. Kim, A mechanistic study of the antibacterial effect of silver ions on Escherichia coli and Staphylococcus aureus, J. Biomed. Mater. Res. 52 (2000) 662-668. 